\title{
Digital ischaemia secondary to steal syndrome from a brachiocephalic arteriovenous fistula
}

\author{
David John Tobias McArdle, David Cottier, Anthony Beasley
}

Royal Hobart Hospital, Hobart, Tasmania, Australia

\section{Correspondence to}

Dr David John Tobias McArdle, david.mcardle@ths.tas.gov.au

Accepted 29 August 2016

\section{DESCRIPTION}

A 68-year-old woman presented with a 6-month history of progressive dry gangrene of her left index and ring fingertips secondary to ischaemic steal syndrome (figure 1). She had end-stage renal failure (requiring dialysis through a left brachiocephalic arteriovenous fistula with a Thoratec stent created 12 months earlier), diabetes, hypertension, ischaemic heart disease and peripheral vascular

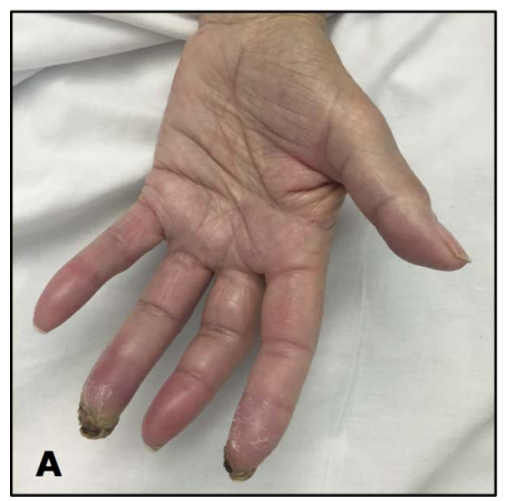

disease. Her symptoms began with reduced sensation and cold fingers, progressing to painful necrotic first and fourth fingertips, a cold hand and absent radial and ulnar pulses. Angiography revealed a high-flow fistula, distal antegrade flow and poor perfusion to the hand (figure 2). She underwent a Revascularisation Using Distal Inflow procedure which involved ligating the fistula at its origin and extending the inflow for the fistula

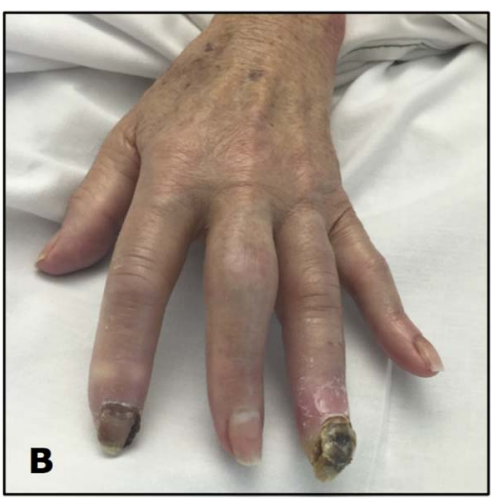

Figure 1 (A) Palmar view of the hand: digital ischaemia evidenced by cold, erythematous and oedematous fingers with dry gangrenous index and ring fingertips; (B) dorsal aspect of the hand showing dry gangrene of the index and ring fingertips.
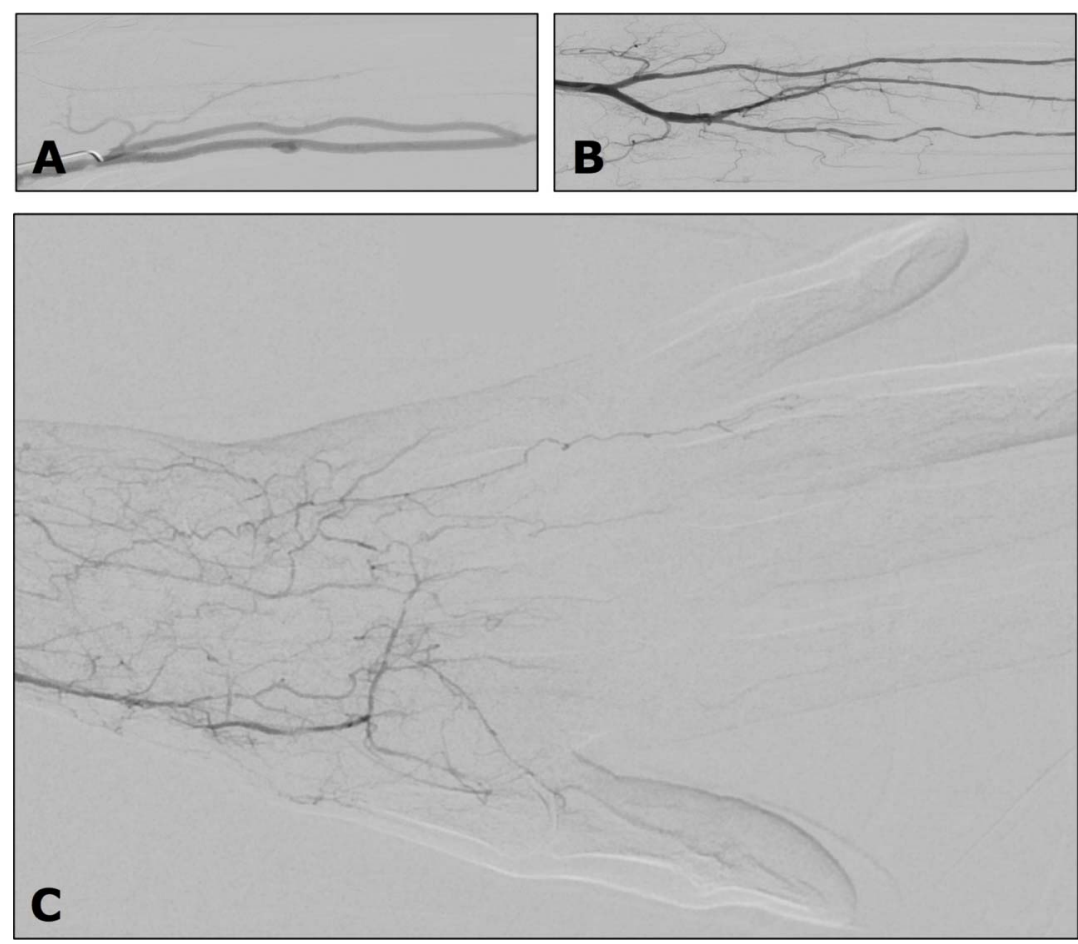

Figure 2 Digital subtraction angiograms showing: (A) a widely patent high-flow brachiocephalic arteriovenous fistula with a Thoratec stent; (B) the bifurcation of the brachial artery with poor flow demonstrated distal to the fistula in the forearm; and (C) significantly diminished radial artery opacification into the hand, near absent ulnar artery supply, a poorly opacified palmar arch and metacarpal arteries, with no direct filling of the digital arteries. 
distally to the radial artery in the midforearm using a segment of the upper arm cephalic vein as the conduit, thus reducing flow in the fistula. At follow-up, the patient had a warm hand, strong radial pulse, improved pain and a patent, functioning fistula.

Steal syndrome, characterised by ischaemic symptoms (pain, paraesthesia and gangrene), is rare, occurring in $<2 \%$ of radiocephalic fistulas and $5-10 \%$ of brachiocephalic fistulas. ${ }^{1}$ Physiological steal always occurs with an arteriovenous fistula. ${ }^{1}$ Symptoms of steal syndrome arise from reduced inflow, outflow obstruction or lack of collateral supply. ${ }^{2-3}$ Risk factors include

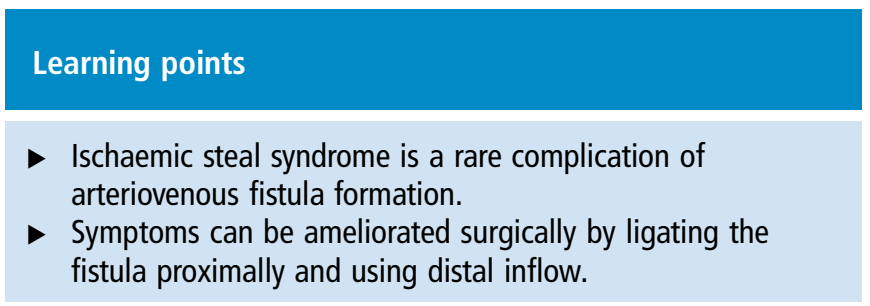

diabetes, atherosclerosis, age $>60$ years and female gender. ${ }^{1}$ Diagnosis is clinical, with signs including pallor, decreased/ absent pulses, sensory and motor neuropathy, distal ulceration or necrosis. ${ }^{1}$ Definitive management is surgical or endovascular, to reduce steal and improve distal flow.

Contributors DJTM was involved in patient care, preparing and submitting the manuscript. DC was the consultant in charge of the patient, performed the operation and reviewed the manuscript. $A B$ performed the digital subtraction angiography and reviewed the manuscript.

Competing interests None declared.

Patient consent Obtained.

Provenance and peer review Not commissioned; externally peer reviewed.

\section{REFERENCES}

1 Zamani P, Kaufman J, Kinlay S. Ischemic steal syndrome following arm arteriovenous fistula for haemodialysis. Vasc Med 2009;14:371-6.

2 Van den Bosch RP, Crowe PM, Mosquera DA. Endovascular treatment of arterial steal secondary to dialysis fistula. Nephrol Dial Transplant 2001;16:2279-80.

3 Valji K, Hye RJ, Roberts AC, et al. Hand ischemia in patients with hemodialysis access grafts: angiographic diagnosis and treatment. Radiology 1995;196:697-701.

Copyright 2016 BMJ Publishing Group. All rights reserved. For permission to reuse any of this content visit http://group.bmj.com/group/rights-licensing/permissions.

BMJ Case Report Fellows may re-use this article for personal use and teaching without any further permission.

Become a Fellow of BMJ Case Reports today and you can:

- Submit as many cases as you like

- Enjoy fast sympathetic peer review and rapid publication of accepted articles

- Access all the published articles

- Re-use any of the published material for personal use and teaching without further permission

For information on Institutional Fellowships contact consortiasales@bmjgroup.com

Visit casereports.bmj.com for more articles like this and to become a Fellow 